Dicle University Journal of Engineering (DUJE)

web: http://dergipark.gov.tr/dumf

Araştırma Makalesi / Research Article

\title{
İçinden Akışkan Geçen Boru Doğal Frekansının Genelleştirilmiş Regresyon Yapay Sinir Ağları Yöntemi İle Tahmini
}

\section{Natural Frequency Estimation of Pipe Conveying Fluid by Using Generalized Regression Neural Networks}

\author{
Begum Yurdanur Dagli ${ }^{1 *}$, Abdulkerim Ergut ${ }^{2}$, Mustafa Erkan Turan ${ }^{3}$ \\ ${ }^{1}$ Manisa Celal Bayar Üniversitesi, Manisa Teknik Bilimler MYO, İnşaat Bölümü, Manisa, begum.dagli@cbu.edu.tr \\ ${ }^{2}$ Manisa Celal Bayar Üniversitesi, İnșaat Mühendisliği Bölümü, Manisa, abdulkerim.ergut @ cbu.edu.tr \\ ${ }^{3}$ Manisa Celal Bayar Üniversitesi, İnşaat Mühendisliği Bölümü, Manisa, mustafaerkan.turan@cbu.edu.tr
}

\begin{tabular}{l} 
MAKALE BİLGİLERİ \\
\hline Makale geçmişi: \\
Geliş: 15 Kasım 2019 \\
Düzeltme: 10 Şubat 2020 \\
Kabul: 10 Mart 2020 \\
\hline Anahtar kelimeler: \\
Akışkan taşıyan boru, dinamik \\
analiz, doğal frekans tahmini, \\
genelleştirilmiş regresyon yapay \\
sinir ağı (GRYSA).
\end{tabular}

Doi: $10.24012 /$ dumf. 647302

\begin{abstract}
ÖZET
Bu çalışmada içinden akışkan geçen silindirik borunun dinamik davranışı farklı mesnet koşulları dikkate alınarak incelenmiștir. Boru Euler-Bernoulli Teorisi kullanılarak modellenmiştir. Dinamik denge altındaki titreşim, ağırlıktan kaynaklanan deplasmanlar ihmal edilerek araştııılmıştır. Boru içerisinden geçen akışkan ideal, kararlı, üniform kabul edilmiştir. Hareket denklemi Hamilton prensibi ile belirlenmiştir. Değişkenler, malzeme ve geometriden bağımsız sonuçlar elde edebilmek için boyutsuzlaştırmıştır. İlk üç mod için çözümler analitik olarak yapılmıştır. Dönme ve ötelemeye karşı farklı direngenlik katsayıları ile temsil edilen mesnet koşulları altında doğal yapılmıştır. Dönme ve ötelemeye karşı farklı direngenlik katsayıları 1le temsıl edilen mesnet koşulları altında doğal
titreşim frekansı değerleri belirlenmiştir. Elde edilen veriler girdi olarak kullanılarak Yapay Sinir Ağları (YSA) ile doğal titreşim frekansı değerleri tahmin edilmiştir. Genelleştirilmiştir Regresyon Yapay Sinir Ağ (GRYSA) ileri beslemeli geriye yayınım metodu (İBGY) uygulanmıştır. Sonuçlar seçilen performans kriterleri kullanılarak karşılaştırılmıştır. Model performansının yüksek olması direngenlik katsayılarına bağlı, akışkan taşıyan boruya ait doğal titreşim frekansının belirlenmesinde GRYSA'nın etkili ve hızlı bir araç olduğunu göstermektedir.
\end{abstract}

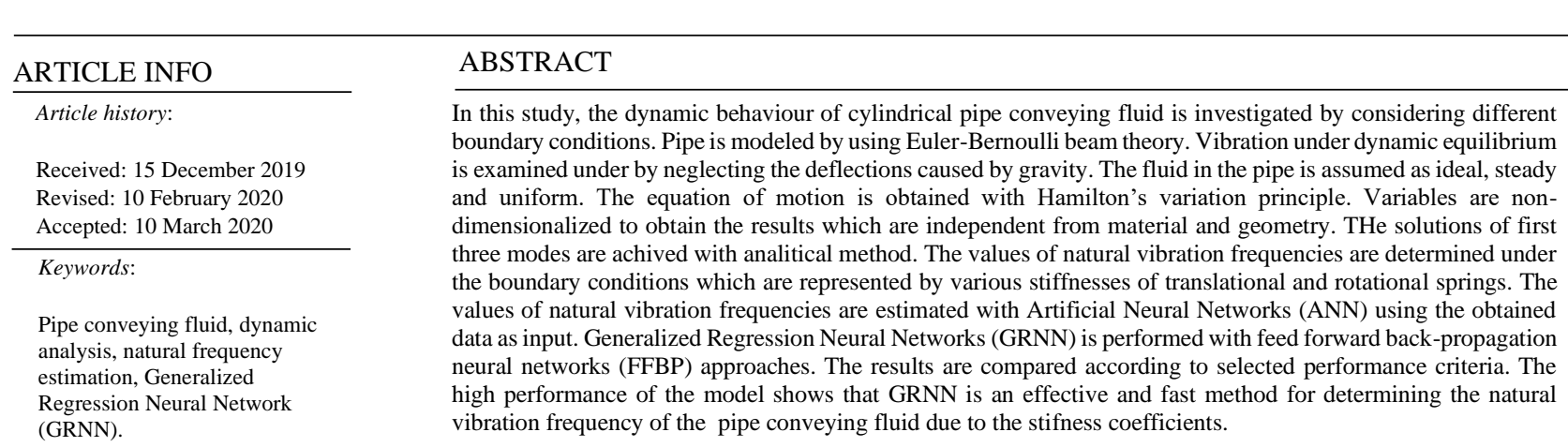

* Sorumlu yazar / Correspondence

Begum Yurdanur Dagli

$\bowtie$ begum.dagli@cbu.edu.tr 


\section{Giriş}

Akışkanların iletiminde kullanılan borular, artan enerji talebi ile birlikte günümüzde daha da yaygın hale gelmiştir. Akışkan hareketinden kaynaklı titreşimin stabilite üzerinde etkili olduğu bu sistemlerde dinamik analiz, tasarım ve projelendirme açısından büyük önem taşımaktadır. Bu nedenle farklı sınır şartlarına ve yükleme koşullarına maruz kalan boru sistemlerinin dinamik davranışına ilişkin birçok kapsamlı çalışma yapılmıştır (Paidoussis ve Issid, 1974; Wiggert ve Tijsseling, 2001; Aldraihem, 2007; Al-Hilli, 2013). Yi-Min vd. (2010) akışkan taşıyan borunun doğal frekansını farklı sınır şartlarını dikkate alarak Galerkin Yöntemi ile belirlemişlerdir. Akışkan hızı ve frekans arasındaki ilişkinin değerlendirdiği çalışmada sonuçlar Coriolis kuvvetinin doğal frekans üzerindeki etkisinin zayıf olduğunu göstermiştir. Zhang vd. (2016) akışkan taşıyan borunun lineer ve nonlineer titreşimini geliştirdikleri hareket denklemlerini kullanarak incelemişlerdir. Lineer model için viskoz sönümün olmadığı durumda boru deplasmanının sürekli arttığı, nonlineer modelde ise kaotik salınımların, akışkan hızındaki küçük bir artışla bile yeniden ortaya çıktığını vurgulamışlardır. Dağlı ve Sınır (2015) klasik olmayan mesnet koşulları altında araştırma yaparak boru titreşim frekansı üzerinde etkili olan parametreleri ortaya koymuşlardır.

$\mathrm{Bu}$ çalışmada içinden akışkan geçen iki ucu mesnetli borunun enine serbest titreşim hareketi incelenmiştir. Dinamik analizde kullanılan boru Euler-Bernoulli Teorisi ile modellenirken, içinden geçen akışkan Euler denklemleri ile temsil edilmiştir. Akışkan-yapı etkileşimi yaklaşımıyla Hamilton prensibi kullanılarak hareket denklemi elde edilmiştir. Sınır şartları, mesnetler için kullanılan $k_{1}, \quad k_{3}$ öteleme direngenlik katsayıları ile $k_{2}, k_{4}$ dönel direngenlik katsayılarına farklı değerler verilerek belirlenmiştir. Boyutsuzlaştırılan diferansiyel denklem çözümleri ilk üç mod yapısı dikkate alınarak gerçekleştirilmiştir. Doluluk oranı $\beta$, ve akışkan hızı $u$, ile değişen doğal frekans $\omega$ değerleri grafikler halinde sunulmuştur.
Ancak bu hesaplamalar uzun zaman almakta ve zahmetli bir süreç gerektirmektedir. Süreyi kısaltmak ve hesaplamayı kolaylaştırmak amacıyla direngenlik katsayıları ve doğal titreșim frekansına ilişkin sonuçlar girdi olarak kullanılarak Genelleştirilmiş Regresyon Yapay Sinir Ağ (GRYSA) yöntemiyle bir tahmin modeli oluşturulmuştur. Eğitim ve test modellerinin performansı, belirlilik katsayısı $\left(\mathrm{R}^{2}\right.$ ), karesel ortalama hata (Root Mean Square Error -RMSE), ortalama mutlak yüzde hata (Mean Absolute Percentage Error-MAPE) ile ölçülmüştür (Cigizoglu ve Kişi, 2005). Tahmin modelinin direngenlik katsayılarına bağlı, akışkan taşıyan boruya ait titreşim frekansının belirlenmesinde etkili olduğu gösterilmiştir.

\section{Materyal ve yöntem \\ Hareketin matematiksel modeli}

Çalışmada kullanılan borunun uzunluğu $L$, kesit alanı $A_{p}$, birim boy kütlesi $m$, olarak kabul edilmiştir. Üniform ve homojen malzemeden üretilen borunun elastisite modülü $E$, yoğunluğu $\rho_{p}$ ve atalet momenti $I$ olarak alınmıştır. Sıkıştırılamaz ideal akışkan için ise kütle, hız ve yoğunluk sirası ile $M, u$ ve $\rho_{f}$, ile temsil edilmiştir. Enine titreşimin en önemli etkisinin eğilme olduğunu ileri sürerek gerilme ile uzama arasında lineer (Han vd.,1999; Liu vd., 2013) bir ilişki kuran Euler-Bernoulli teorisine göre borunun potansiyel enerjisi

$U=\frac{1}{2} \int_{0}^{L} E^{*} I^{*}\left(\frac{\partial^{2} v^{*}\left(x^{*}, t^{*}\right)}{\partial x^{*}}\right)^{2} d x^{*}$

şeklindedir. Burada $v^{*}\left(x^{*}, t^{*}\right), x^{*}$ konumunda ve $t^{*}$ anındaki enine deplasmanı göstermektedir. Boyutlu değişkenler * sembolü ile belirtilmiştir. Yanal yer değiştirmeye bağlı kinetik enerji

$T=\frac{1}{2} \int_{0}^{L} \rho_{p}^{*} A_{p}^{*}\left(\frac{\partial v^{*}\left(x^{*}, t^{*}\right)}{\partial x^{*}}\right)^{2} d x^{*}$

bağıntısı ile verilmiştir. Düzlemsel hareketin modellenmesi için kullanılan Hamilton Prensibi

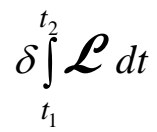


olarak gösterilmiştir. Lagrange terimi, $\mathcal{L}=T-U$ ile ifade edilmektedir. Bu durumda bir bağıml, iki bağımsız değișken için Euler Bernoulli modeli ile elde edilen hareket denklemi

$\rho_{p}{ }^{*} A_{p}{ }^{*} \ddot{v}^{*}+E^{*} I^{*} v^{* I V}=0$

şeklinde yazılır. Diferansiyel denklemde, zamana bağl1 türev ( ' ) ile konuma bağl1 türev ise ( )' ifadesi ile gösterilmiştir. Borunun içinden geçen akışkan ideal kabul edildiğinden Euler denklemi olarak bilinen sürtünmesiz akışa ait genel bağıntı (Munson vd., 2013).

$\frac{\partial P}{\partial y^{*}}=\rho_{f} Y-\rho_{f} a_{y}$

olarak elde edilir. Burada $y$ düşey doğrultu olmak üzere, $a_{y}$, akışkan ivmesinin düşey bileşenini temsil etmektedir. $P$ ve $Y$ ise sırası ile basınç ve dış kuvveti göstermektedir. Boru ve içinden geçen akışkana ilişkin verilen denklemler akışkan-yapı etkileşimi yaklaşımı ile birleştirilerek sistemin hareketi Denklem (6) ile tanımlanır.

$\rho_{p} A_{p} \ddot{v}^{*}+\rho_{f} A_{f}\left(\ddot{v}^{*}+2 u^{*} \dot{v}^{\prime}+u^{* 2} v^{* \prime}\right)+E I v^{* I V}=0$

Hareket denklemini malzemeden bağımsız hale getirmek için kullanılan boyutsuz deplasman $v$, konum $x$, zaman $t$ ve akışkan hızı $u$ aşağıda verilmiștir.

$v=\frac{v^{*}}{L}, x=\frac{x^{*}}{L}$

$t=t^{*} \sqrt{\frac{E I}{L^{4}(m+M)}}, u=u^{*} \frac{\sqrt{M}}{\sqrt{E I}} L$

Boyutsuz ifadelerin Denklem (6)' da yazılması ile elde edilen akışkan tanıyan boruya ilişkin hareket denklemi

$v^{v v}+u^{2} v^{\prime \prime}+2 \sqrt{\beta} u \dot{v}^{\prime}+\ddot{v}=0$

şeklindedir. Boyutsuzlaştırma ile elde edilen $\beta$, doluluk oranı olarak adlandırılır ve akıșkan kütlesinin toplam kütleye oranı $M /(m+M)$ olarak ifade edilir (Paidoussis, 1974).

\section{Analitik çözüm yöntemi}

Matematiksel modeli oluşturulan (EulerBernoulli) akışkan taşıyan boruya ait lineer diferansiyel hareket denklemi için genel çözüm

$v(x, t)=X_{n}(x) e^{i \omega_{n} t}+\bar{X}_{n}(x) e^{-i \omega_{n} t}$

şeklindedir. Burada $X_{n}$, Coriolis terimine bağlı kompleks fonksiyonu temsil etmektedir. Doğal tireşim frekansı ise $\omega_{n}$, ile gösterilmiştir. Denklem (9), Denklem (6) da yerine yazıldığında Denklem (10) elde edilir.

$X^{w}+u^{2} X^{\prime \prime}+2 \sqrt{\beta} u i \omega X^{\prime}-\omega^{2} X=0$

Denklemin çözümü için Şekil 1'de akış diyagramı verilen yazılımdan yararlanılmıştır (Dagli ve Ergut, 2019).

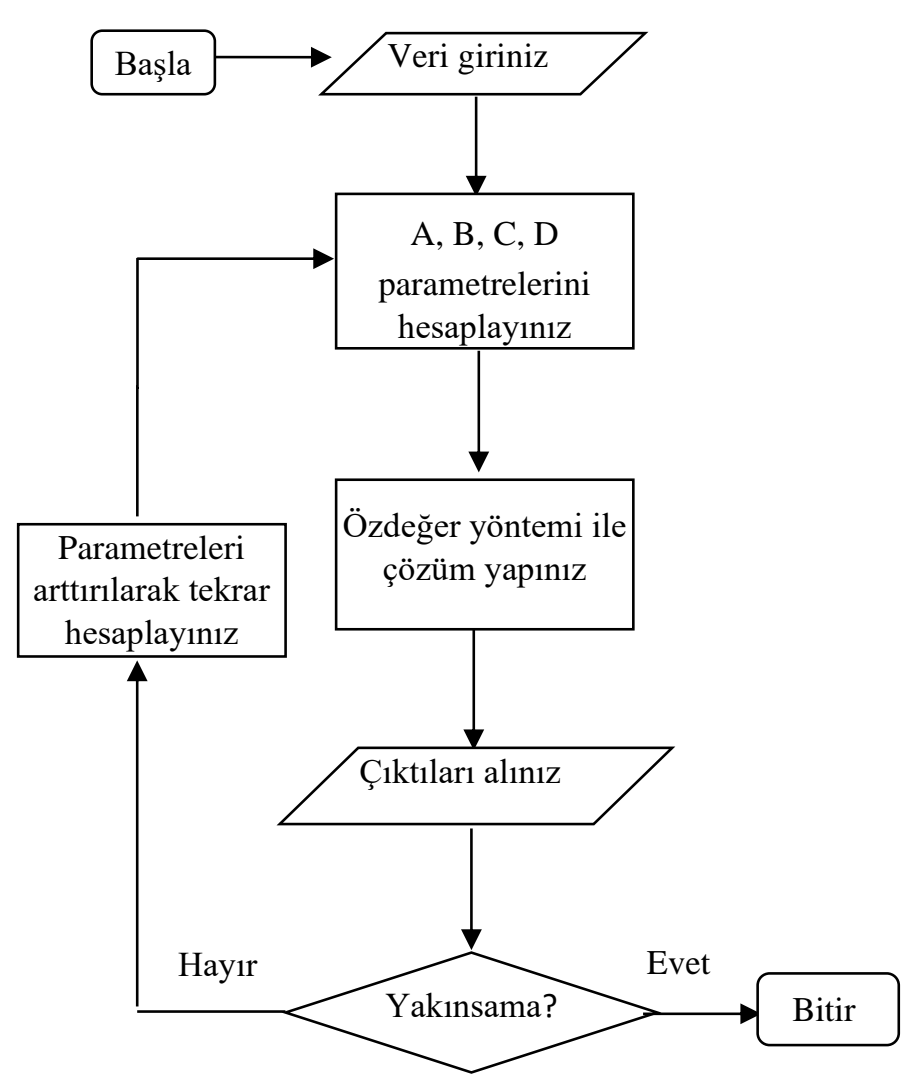

Şekil 1. Akış diyagramı

Figure 1. Flow chart

Akış diyagramında hesaplanması istenen $A, B, C, D$ parametreleri 


$$
A=-\omega_{n}^{2}, \quad B=2 \sqrt{\beta} u i \omega_{n}, \quad C=u^{2}, \quad D=1
$$

olarak verilmiştir. Sınır şartları, mesnetler için kullanılan $k_{1}, k_{3}$ öteleme direngenlik katsayıları ve $k_{2}, k_{4}$ dönel direngenlik katsayıları dikkate alınarak Şekil 2'de gösterilmektedir.

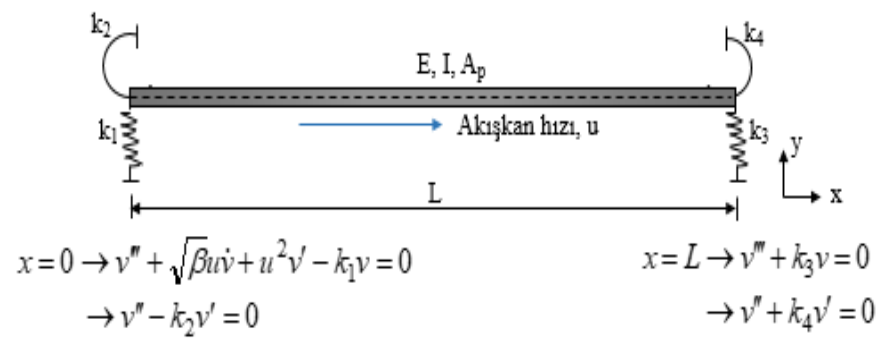

Şekil 2. Akışkan taşıyan boru sınır şartları

Figure 2. Boundary conditions of pipe conveying fluid

Borunun başında ve sonunda sınır şartlarının farklı olması $x=L$ noktasında akışkanın serbest kalmasından kaynaklanmaktadır (Aldraihem, 2007).

Boyutsuz direngenlik katsayıları

$k_{1}=k_{1}^{*} \frac{L^{3}}{E I}, \quad k_{2}=k_{2}^{*} \frac{L}{E I}, \quad k_{3}=k_{3}^{*} \frac{L^{3}}{E I}, \quad k_{4}=k_{4}^{*} \frac{L}{E I}$

şeklinde verilmiştir. Çalışma kapsamında direngenlik katsayıları borunun iki ucunun da dönme serbestliğinin olduğu basit mesnet, çökme ve dönmeye karşı rijit olan ankastre mesnet koşulları dikkate alınarak, klasik sınır şartları altında değerlendirilmiştir. Ayrıca katsayılara 5,00 ile 1000,00 arasında 16 farklı değer verilerek klasik olmayan elastik mesnet koşulları da incelenmiştir. Elde edilen sonuçlardan veri seti oluşturulmuştur.

\section{Genelleștirilmiş Regresyon Yapay Sinir A}

Specht tarafindan 1991 yılında geliştirilen Genelleștirilmiş Regresyon Yapay Sinir Ağları (GRYSA) yönteminde girdi ve çıktı verileri yardımı ile oluşturulan tahmin fonksiyonundan yararlanılmaktadır (Samarasinghe, 2016; Tayfur, 2017). GRYSA, girdi, örüntü, toplama ve çıtı katmanı olmak üzere dört katmandan meydana gelen bir yapıya sahiptir

Yöntem iteratif eğitim prosedürü gerektirmemektedir. Girdi ve çıtılır arasındaki ilişkiyi tanımlayan fonksiyon doğrudan eğitim verisi yardımı ile belirlenmektedir (Alp \& Cigizoglu, 2010). Bağımlı değişken olan y'nin bağımsız değişken $x$ 'e göre regresyonu, $y$ için en olası değeri vermektedir. En küçük kareler yöntemi ile regresyon tekniği kullanılarak y'nin tahmini değerleri elde edilmektedir. Olasılık yoğunluk fonksiyonu olan $f(x, y)$, bilinmiyor ise gözlenen $X^{i}$ ve $Y^{i}$ arasındaki ilişki kullanılarak tahmin yapilır ve regresyon

$$
\hat{Y}(X)=\frac{\sum_{i=1}^{n} Y^{i} \exp \left(-\frac{\left(X-X^{i}\right)^{T}\left(X-X^{i}\right)}{2 s^{2}}\right)}{\sum_{i=1}^{n} \exp \left(-\frac{\left(X-X^{i}\right)^{T}\left(X-X^{i}\right)}{2 s^{2}}\right)}
$$

şeklinde hesaplanır. Bağıntıda geçen ve belirlenmesi gereken $s$, düzeltme parametresini temsil etmektedir.

Tüm veri setindeki çıtılar her bir mod için borunun \%10 dolu olmasın durumu göz önüne alınarak hesaplanan doğal frekanslardan oluşmakta olup 129 adet $\omega_{1}, 129$ adet $\omega_{2}$ ve 129 adet $\omega_{3}$ değerinden meydana gelmektedir. Toplamda 387 adet çıktı değerini elde etmekte kullanılan girdiler ise akışkan hızı $u$, öteleme direngenlik katsayıları $k_{1}, k_{3}$ ve dönel direngenlik katsayıları $k_{2}, k_{4}$ olmak üzere 5 adettir. Tüm verilerin $\% 75^{\prime}$ i eğitim veri seti, \%25'i test veri setini oluşturmaktadır. Eğitim ve test veri setlerindeki değerler rastgele olarak seçilmiştir.

Çalışmada doğal frekansları tahmin etmek amacıyla farklı çıktı yapısına sahip toplam 4 adet model oluşturulmuştur. $\mathrm{Bu}$ modellerin girdi ve çıktı yapıları Tablo 1'de verilmiştir.

Tablo 1. GRYSA modeli girdi ve çıktı yapıları Table 1. GRNN Model input and output structures 


\begin{tabular}{ccc}
\hline Model No & $\begin{array}{c}\text { Girdi } \\
\text { Değişkenleri }\end{array}$ & Çıktı Yapısı \\
\hline Model 1 & $\mathrm{u}, \mathrm{k}_{1}, \mathrm{k}_{2}, \mathrm{k}_{3}, \mathrm{k}_{4}$ & $\omega_{1}$ \\
Model 2 & $\mathrm{u}, \mathrm{k}_{1}, \mathrm{k}_{2}, \mathrm{k}_{3}, \mathrm{k}_{4}$ & $\omega_{2}$ \\
Model 3 & $\mathrm{u}, \mathrm{k}_{1}, \mathrm{k}_{2}, \mathrm{k}_{3}, \mathrm{k}_{4}$ & $\omega_{3}$ \\
Model 4 & $\mathrm{u}, \mathrm{k}_{1}, \mathrm{k}_{2}, \mathrm{k}_{3}, \mathrm{k}_{4}$ & $\omega_{1}, \omega_{2}, \omega_{3}$ \\
\hline
\end{tabular}

Yap1s1 gereği GRYSA'da sadece düzeltme parametresi $s$ 'nin belirlenmesi gerekmektedir. Çalışmada $s$ parametresi deneme yanılma yöntemi ile değeri tüm modeller için 0,1 olarak belirlenmiştir.

Modellerin performansları belirlilik katsayıs $\left(R^{2}\right)$, hata karelerinin karekökü (RMSE) ve ortalama mutlak yüzde hata $(M A P E)$ değerleri kullanılarak belirlenmiştir. Modelin performans ölçütü olarak kullanılan belirlilik katsayısı $R^{2}$

$$
R^{2}=\left[\frac{\sum_{i=1}^{N}\left(\omega_{(g)}(t)-\bar{\omega}_{(g)}\right)\left(\omega_{(h)}(t)-\bar{\omega}_{(h)}\right)}{\sqrt{\sum_{i=1}^{N}\left(\omega_{(g)}(t)-\bar{\omega}_{(g)}\right)^{2}\left(\omega_{(h)}(t)-\bar{\omega}_{(h)}\right)^{2}}}\right]^{2}
$$

şeklinde ifade edilmektedir. Ortalama hata karelerinin karekökü RMSE

$$
R M S E=\sqrt{\frac{1}{N} \sum_{i=1}^{N}\left(\omega_{(g)}-\omega_{(h)}\right)^{2}}
$$

bağıntısı ile hesaplanmaktadır. Ortalama mutlak yüzde hata $M A P E$

$$
M A P E=\frac{100}{N} \sum_{i=1}^{N}\left|\frac{\omega_{(g)}-\omega_{(h)}}{\omega_{(g)}}\right|
$$

şeklindedir. Burada $\omega(\mathrm{g})$, hesaplanan doğal frekans değerlerini, $\omega(\mathrm{h})$, tahmin edilen doğal frekans değerlerini, $N$, veri sayısını göstermektedir.

\section{Bulgular ve değerlendirme \\ Doğal frekans analizi sonuçları}

Tablo 2'de görülen doğal frekans değerleri klasik mesnet koşulları altında elde edilmiştir. Sabit mesnet, ankastre mesnet sınır şartları ile oluşturulan boru modeline ilişkin direngenlik katsayıları tabloda görülmektedir.

Borunun içinden geçen boyutsuz akışkan hızı $0,20,0,50$ ve 0,80 alınarak yapılan araştırmada direngenlik katsayısı arttıkça doğal titreşim frekansı da artmaktadır. En büyük doğal frekans değerleri ankastre-ankastre mesnet koşulları altında elde edilmiştir.

Akışkan hızındaki artış ise doğal frekans değerlerinin düşmesine sebep olmaktadır. $\mathrm{Bu}$ nedenle aynı sınır koşulları dikkate alındığında akışkan hızının 0,80 olduğu durumda elde edilen sonuçlar en düşük değerlerden oluşmaktadır.

Yaygın olarak kullanılan klasik mesnet koşullarının yanı sıra klasik olmayan; elastik çöken, elastik dönen mesnet koşulları da, farklı direngenlik katsayıları tanımlanarak incelenmiştir. 10 farklı direngenlik katsayısı için işlemler tekrarlanmış ve doğal frekansta meydana gelen değişim değerlendirilmiştir. Öncelikli olarak $k_{1}$ ve $k_{2}$ 'nin farklı değerler aldığı, diğer direngenlik katsayılarının 1,00 kabul edildiği koşul ele alınmıştır. Sonuçlar Tablo 3'de verilmiştir. 
Tablo 2. Klasik mesnet koşulları altında doğal titreşim frekansı değerleri $(\beta=0,10)$

Table 2. The values of natural vibration frequencies under classical boundary conditions $(\beta=0,10)$

\begin{tabular}{|c|c|c|c|c|c|c|c|c|}
\hline Koşul & $u$ & $k_{1}$ & $k_{2}$ & $k_{3}$ & $k_{4}$ & $\omega_{1}$ & $\omega_{2}$ & $\omega_{3}$ \\
\hline Sabit -sabit & & $\infty$ & 0 & $\infty$ & 0 & 9,8499 & 39,4580 & 88,8059 \\
\hline Ankastre-ankastre & 0,20 & $\infty$ & $\infty$ & $\infty$ & $\infty$ & 22,3629 & 61,6576 & 120,8866 \\
\hline Ankastre-sabit & & $\infty$ & $\infty$ & $\infty$ & 0 & 15,4038 & 49,9474 & 104,2291 \\
\hline Sabit -sabit & & $\infty$ & 0 & $\infty$ & 0 & 9,7462 & 39,3509 & 88,6977 \\
\hline Ankastre-ankastre & 0,50 & $\infty$ & $\infty$ & $\infty$ & $\infty$ & 22,3082 & 61,5778 & 120,7982 \\
\hline Ankastre-sabit & & $\infty$ & $\infty$ & $\infty$ & 0 & 15,3276 & 49,8555 & 104,1317 \\
\hline Sabit -sabit & & $\infty$ & 0 & $\infty$ & 0 & 9,3657 & 38,9656 & 88,3104 \\
\hline Ankastre-ankastre & 0,80 & $\infty$ & $\infty$ & $\infty$ & $\infty$ & 22,1117 & 61,2914 & 120,4821 \\
\hline Ankastre-sabit & & $\infty$ & $\infty$ & $\infty$ & 0 & 15,0522 & 49,5258 & 103,7827 \\
\hline
\end{tabular}

Tablo 3. Klasik olmayan mesnet koşulları altında doğal titreşim frekansı değerleri $(\beta=0,10)$

Table 3. The values of natural vibration frequencies under non-classical boundary conditions $(\beta=0,10)$

\begin{tabular}{|c|c|c|c|c|c|c|c|c|}
\hline$u$ & $k_{I}$ & $\omega_{1}$ & $\omega_{2}$ & $\omega_{3}$ & $k_{2}$ & $\omega_{1}$ & $\omega_{2}$ & $\omega_{3}$ \\
\hline \multirow{10}{*}{0,20} & 5,00 & 2,4014 & 25,0225 & 64,9667 & 5,00 & 5,3363 & 28,1961 & 69,1384 \\
\hline & 10,00 & 1,8779 & 24,6743 & 64,8210 & 10,00 & 5,8249 & 29,4914 & 71,4258 \\
\hline & 20,00 & 1,6272 & 24,0189 & 64,5347 & 20,00 & 6,1307 & 30,0375 & 73,3550 \\
\hline & 30,00 & 1,5498 & 23,4231 & 64,2554 & 30,00 & 6,2446 & 30,8450 & 74,2022 \\
\hline & 40,00 & 1,5124 & 22,8892 & 63,9830 & 40,00 & 6,3040 & 31,0576 & 74,6770 \\
\hline & 50,00 & 1,4904 & 22,4159 & 63,7177 & 50,00 & 6,3406 & 31,1909 & 74,9803 \\
\hline & 250,00 & 1,4219 & 19,0917 & 59,7736 & 250,00 & 6,4620 & 31,6495 & 76,0568 \\
\hline & 500,00 & 1,4135 & 18,3968 & 57,2915 & 500,00 & 6,4777 & 31,7106 & 76,2039 \\
\hline & 750,00 & 1,4107 & 18,1556 & 56,0193 & 750,00 & 6,4830 & 31,7311 & 76,2536 \\
\hline & 1000,00 & 1,4056 & 18,0337 & 55,2711 & 1000,00 & 6,4856 & 31,7414 & 76,2785 \\
\hline \multirow{10}{*}{0,50} & 5,00 & 2,2736 & 24,8365 & 64,8071 & 5,00 & 5,1302 & 28,0381 & 68,9938 \\
\hline & 10,00 & 1,5676 & 24,4856 & 64,6611 & 10,00 & 5,6349 & 29,3418 & 71,2881 \\
\hline & 20,00 & 1,3557 & 23,8259 & 64,3742 & 20,00 & 5,9486 & 30,3083 & 73,2219 \\
\hline & 30,00 & 1,2899 & 23,2273 & 64,0942 & 30,00 & 6,0650 & 30,7019 & 74,0709 \\
\hline & 40,00 & 1,2579 & 22,6920 & 63,8214 & 40,00 & 6,1257 & 30,9152 & 74,5465 \\
\hline & 50,00 & 1,2390 & 22,2185 & 63,5556 & 50,00 & 6,1630 & 31,0490 & 74,8504 \\
\hline & 250,00 & 1,1799 & 18,9223 & 59,2732 & 250,00 & 6,2867 & 31,5092 & 75,9285 \\
\hline & 500,00 & 1,1727 & 18,2384 & 57,1355 & 500,00 & 6,3027 & 31,5704 & 76,0757 \\
\hline & 750,00 & 1,1703 & 18,0011 & 55,8687 & 750,00 & 6,3081 & 31,5910 & 76,1255 \\
\hline & 1000,00 & 1,1691 & 17,8812 & 55,1241 & 1000,00 & 6,3108 & 31,6013 & 76,1505 \\
\hline
\end{tabular}


Tablo 3. Devam

Table 3. Continuation

\begin{tabular}{ccccccccc}
\hline $\boldsymbol{u}$ & $\boldsymbol{k}_{\boldsymbol{I}}$ & $\boldsymbol{\omega}_{\boldsymbol{1}}$ & $\boldsymbol{\omega}_{2}$ & $\boldsymbol{\omega}_{3}$ & $\boldsymbol{k}_{2}$ & $\boldsymbol{\omega}_{\boldsymbol{1}}$ & $\boldsymbol{\omega}_{2}$ & $\boldsymbol{\omega}_{3}$ \\
\hline 5,00 & 1,1771 & 24,4870 & 64,5097 & 5,00 & 4,7235 & 27,7422 & 68,7246 \\
& 10,00 & 0,8182 & 24,1310 & 64,3630 & 10,00 & 5,2638 & 29,0617 & 71,0317 \\
& 20,00 & 0,6433 & 23,4633 & 64,0749 & 20,00 & 5,5945 & 30,4531 & 72,9743 \\
& 30,00 & 0,5838 & 22,8594 & 63,7939 & 30,00 & 5,7163 & 30,4342 & 73,8265 \\
& 40,80 & 0,5535 & 22,3215 & 63,5201 & 40,00 & 5,7796 & 30,6491 & 74,3037 \\
& 50,00 & 0,5351 & 21,8477 & 63,2534 & 50,00 & 5,8185 & 30,7838 & 74,6085 \\
& 250,00 & 0,4745 & 18,6044 & 59,3080 & 250,00 & 5,9472 & 31,2468 & 75,6896 \\
& 500,00 & 0,4667 & 17,9409 & 56,8450 & 500,00 & 5,9638 & 31,3083 & 75,8372 \\
& 750,00 & 0,4641 & 17,7110 & 55,5881 & 750,00 & 5,9693 & 31,3291 & 75,8870 \\
& 1000,00 & 0,4627 & 17,5948 & 54,8502 & 1000,00 & 5,9721 & 31,3394 & 75,9121 \\
\hline
\end{tabular}

Tablo 3 'de verilen koşulların $k_{2}$ ve $k_{4}$ direngenlik katsayıları açısından değerlendirilmemesi sistemin simetrik olmasindan kaynaklanmaktadır. Elde edilen sonuçlardan görüldüğü gibi rijitlik arttıkça, doğal frekans değerleri azalmaktadır. İkinci aşamada direngenlik katsayıları ikişerli gruplar halinde değiştirilerek sonuçlar değerlendirilmiştir. $k_{1}, k_{3}$ direngenlik katsayıs $50,00,1000,00$ arasında değerler alırken diğer direngenlik katsayıları 1,00 olarak kabul edilmiştir.

Daha sonra $k_{2}$, $k_{4}$ 'e 50,00 ile 1000,00 arasinda değer verilerek elde edilen doğal frekans değerleri Tablo 4'de sunulmuştur.

Tablo 4. Klasik olmayan mesnet koşulları altında doğal titreşim frekansı değerleri $(\beta=0.10)$

Table 4. The values of natural vibration frequencies under non-classical boundary conditions $(\beta=0.10)$

\begin{tabular}{ccccccccc}
\hline $\boldsymbol{u}$ & $\boldsymbol{k}_{\boldsymbol{1}}, \boldsymbol{k}_{3}$ & $\boldsymbol{\omega}_{1}$ & $\boldsymbol{\omega}_{2}$ & $\boldsymbol{\omega}_{3}$ & $\boldsymbol{k}_{2}, \boldsymbol{k}_{4}$ & $\boldsymbol{\omega}_{1}$ & $\boldsymbol{\omega}_{2}$ & $\boldsymbol{\omega}_{3}$ \\
\hline 50,00 & 18,7625 & 62,2812 & 122,9653 & 50,00 & 9,2557 & 37,9565 & 85,6223 \\
& 60,00 & 17,7867 & 61,7364 & 122,6630 & 60,00 & 9,3177 & 38,1811 & 86,0993 \\
& 70,00 & 16,9715 & 61,2022 & 122,3632 & 70,00 & 9,3627 & 38,3456 & 86,4513 \\
& 80,00 & 16,3005 & 60,6791 & 122,0658 & 80,00 & 9,3968 & 38,4712 & 86,7218 \\
& 90,00 & 15,7508 & 60,1674 & 121,7708 & 90,00 & 9,4235 & 38,5702 & 86,9361 \\
& 100,00 & 15,2990 & 59,6677 & 121,4783 & 100,00 & 9,4451 & 38,6503 & 87,1101 \\
& 250,00 & 12,8958 & 53,6892 & 117,4013 & 250,00 & 9,5638 & 39,0971 & 88,0905 \\
& 500,00 & 12,1826 & 48,6169 & 111,9232 & 500,00 & 9,6043 & 39,2515 & 88,4334 \\
& 750,00 & 11,9591 & 46,3403 & 107,9023 & 750,00 & 9,6179 & 39,3036 & 88,5496 \\
& 1000,00 & 11,8501 & 45,1152 & 104,9751 & 1000,00 & 9,6247 & 39,3298 & 88,6081 \\
\hline
\end{tabular}


Tablo 4. Devam

Table 4. Continuation

\begin{tabular}{|c|c|c|c|c|c|c|c|c|}
\hline$u$ & $k_{1}, k_{3}$ & $\omega_{1}$ & $\omega_{2}$ & $\omega_{3}$ & $k_{2}, k_{4}$ & $\omega_{1}$ & $\omega_{2}$ & $\omega_{3}$ \\
\hline \multirow{10}{*}{0,50} & 50,00 & 18,5451 & 62,1159 & 122,8188 & 50,00 & 9,1487 & 37,8525 & 85,5184 \\
\hline & 60,00 & 17,5746 & 61,5702 & 122,5162 & 60,00 & 9,2115 & 38,0778 & 85,9961 \\
\hline & 70,00 & 16,7675 & 61,0351 & 122,2161 & 70,00 & 9,2569 & 38,2427 & 86,3487 \\
\hline & 80,00 & 16,1057 & 60,5113 & 121,9185 & 80,00 & 9,2914 & 38,3687 & 86,6195 \\
\hline & 90,00 & 15,5650 & 59,9990 & 121,6232 & 90,00 & 9,3185 & 38,4680 & 86,8341 \\
\hline & 100,00 & 15,1217 & 59,4988 & 121,3305 & 100,00 & 9,3403 & 38,5483 & 87,0083 \\
\hline & 250,00 & 12,7723 & 53,5241 & 117,2516 & 250,00 & 9,4603 & 38,9963 & 87,9899 \\
\hline & 500,00 & 12,0756 & 48,4719 & 111,7749 & 500,00 & 9,5012 & 39,1511 & 88,3332 \\
\hline & 750,00 & 11,8572 & 46,2086 & 107,7583 & 750,00 & 9,5150 & 39,2033 & 88,4495 \\
\hline & 1000,00 & 11,7506 & 44,9913 & 104,8361 & 1000,00 & 9,5219 & 39,2295 & 88,5081 \\
\hline \multirow{10}{*}{0,80} & 50,00 & 18,1375 & 61,8078 & 122,5461 & 50,00 & 8,9470 & 37,6587 & 85,3253 \\
\hline & 60,00 & 17,1780 & 61,2603 & 122,2431 & 60,00 & 9,0112 & 37,8852 & 85,8043 \\
\hline & 70,00 & 16,3869 & 60,7237 & 121,9426 & 70,00 & 9,0576 & 38,0510 & 86,1577 \\
\hline & 80,00 & 15,7427 & 60,1985 & 121,6444 & 80,00 & 9,0929 & 38,1777 & 86,4292 \\
\hline & 90,00 & 15,2194 & 59,6851 & 121,3488 & 90,00 & 9,1205 & 38,2775 & 86,6443 \\
\hline & 100,00 & 14,7920 & 59,1840 & 121,0557 & 100,00 & 9,1428 & 38,3583 & 86,8189 \\
\hline & 250,00 & 12,5419 & 53,2168 & 116,9733 & 250,00 & 9,2653 & 38,8084 & 87,8028 \\
\hline & 500,00 & 11,8754 & 48,2022 & 111,4991 & 500,00 & 9,3070 & 38,9639 & 88,1468 \\
\hline & 750,00 & 11,6662 & 45,9637 & 107,4906 & 750,00 & 9,3211 & 39,0164 & 88,2634 \\
\hline & 1000,00 & 11,5641 & 44,7609 & 104,5777 & 1000,00 & 9,3281 & 39,1764 & 88,3220 \\
\hline
\end{tabular}

Hesaplanan doğal frekans değerleri incelendiğinde her üç mod için de akışkan hızı arttıkça frekans azalmaktadır. Direngenlik katsayıları artıkça ise rijitlik artmakta ve buna bağlı olarak frekans yine düşmektedir. Ancak direngenliğin 50,00 ve 1000,00 arasındaki değişimi dikkate alındığında 250,00'den sonra direngenlik katsayılarının frekans üzerindeki etkisinin azaldığ 1 görülmektedir. Frekanslar arasındaki rölatif fark \% 0,5 ile \% 0,009 arasında değerler almakta özellikle 1 . mod için yakınsama artmaktadır. Tablo 3 'de doğal frekans değerleri arasında elde edilen en büyük fark $\approx \% 30$ olarak, akışkan hızının 0,80, direngenlik katsayısının 5 ile 10 olduğu koşullar altında hesaplanmıştır.

Direngenlik katsayılarının ikişerli olarak değiştirildiği şartlar değerlendirildiğinde ise en büyük fark direngenlik katsayısının 50,00 ve 60,00 değerlerini aldığ 1 aralıkta, $\approx \% 5$ olarak hesaplanmıştır. Bu koşullarda akışkan hızının değişiminin, doğal frekans değerleri arasında oluşan fark üzerindeki etkisi ihmal edilebilecek kadar azdır.

$\mathrm{Bu}$ da akışkan hızının, direngenlik katsayısının $k<50,00$ olması durumunda, doğal titreşim 
frekansı üzerinde etkisi olan önemli bir parametre olduğunu göstermektedir.

\section{GRYSA Sonuçları}

290 adet eğitim verisi kullanılarak GRYSA yöntemi ile oluşturulan tahmin fonksiyonunun belirlenen 4 model için performans değerleri Tablo 5'de verilmiştir.

Tablo 5. GRYSA eğitim aşaması sonuçları

Table 5. GRNN training results

\begin{tabular}{cccc}
\hline \multirow{2}{*}{ Model } & \multicolumn{3}{c}{ YSA Eğitim Modeli } \\
& $\mathrm{R}^{2}$ & RMSE & MAPE \\
\hline Model 1 & 1 & 0,000605428 & 0,02542662 \\
\hline Model 2 & 1 & 0,00037066 & 0,00094226 \\
\hline Model3 & 1 & 0,000325079 & 0,00035397 \\
\hline Model 4 $\omega_{1}$ & 1 & 0,000622539 & 0,02573317 \\
\hline Model 4 $\omega_{2}$ & 1 & 0,000366469 & 0,000968389 \\
\hline Model 4 $\omega_{3}$ & 1 & 0,000334978 & 0,000354454 \\
\hline
\end{tabular}

Tablo 5' de bulunan eğitim aşaması sonuçları incelendiğinde tüm modeller için eğitim veri sayısının yeterli büyüklükte olması nedeniyle yüksek $R^{2}$ ile düşük $R M S E$ ve $M A P E$ değerleri elde edilmiştir. Modellerin tahmin kabiliyetini gösteren değer ise test aşamasında elde edilen değerlerdir.

97 adet test verisi ile tahmin fonksiyonunun performansı değerlendirilmiş ve sonuçlar Tablo 6 ile verilmiştir.

Tablo 6'da verilen test aşaması sonuçlarında Model 1 ile tahmin edilen $\omega_{1}$ değerleri için $R^{2}$ 'nin bire oldukça yakın, RMSE değerinin ise küçük olduğu görülmektedir. $M A P E$ değeri diğer modellere göre büyük olsa da bu $M A P E$ değeri $\% 10,62$ ortalama hata yapıldığını ifade etmektedir. Aynı durum 3 doğal frekans değerinin tek bir model ile tahmin edildiği Model 4 için de geçerlidir. Model 4' te $\omega_{I}$ için MAPE değeri \%13,99 olarak elde edilmiştir. $\boldsymbol{\omega}_{2}$ ve $\omega_{3}$ değerlerinin tahminleri Model 2, Model 3 ve Model 4 ile yapılmıştır. Tüm modellerde bire yakın $R^{2}$ ile düşük $R M S E$ ve $M A P E$ değerleri elde edilmiştir.

\section{Tablo 6. GRYSA test aşaması sonuçları}

Table 6. GRNN testing results

\begin{tabular}{cccc}
\hline \multirow{2}{*}{ Model } & \multicolumn{3}{c}{ YSA Eğitim Modeli } \\
& $\mathrm{R}^{2}$ & RMSE & MAPE \\
\hline Model 1 & 0,997336 & 0,2942068 & 10,62085 \\
\hline Model 2 & 0,999814 & 0,2253451 & 0,602711 \\
\hline Model3 & 0,999911 & 0,2349525 & 0,241307 \\
\hline Model 4 $\omega_{1}$ & 0,997158 & 0,2774114 & 13,99024 \\
\hline Model 4 $\omega_{2}$ & 0,999737 & 0,2068457 & 0,581803 \\
\hline Model 4 $\omega_{3}$ & 0,999908 & 0,1989003 & 0,224142 \\
\hline
\end{tabular}

Şekil 3' te sırası ile tüm modellerin test aşamaları için saçılma diyagramları bulunmaktadır. Diyagramların performans değerleri ile uyumlu olduğu ve hesaplanan-tahmin edilen değer çiftlerinin $45^{\circ}$ eğime sahip bir doğru üzerinde bulundukları görülmektedir.

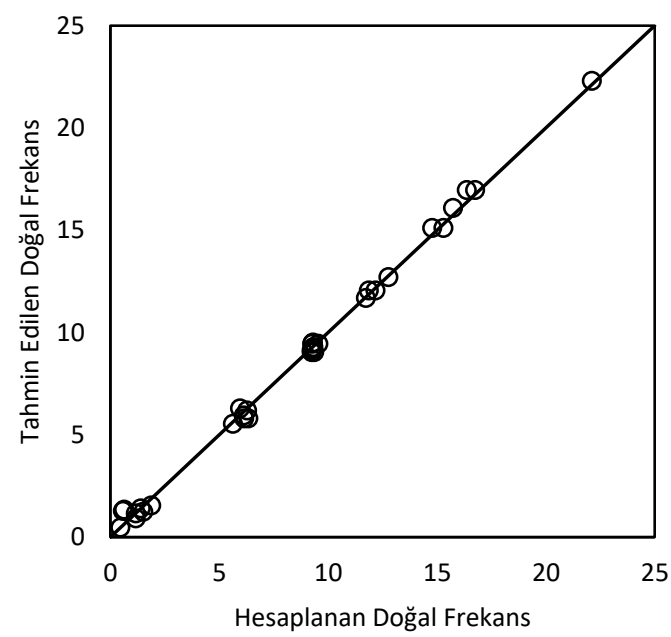

(a) Model 1 


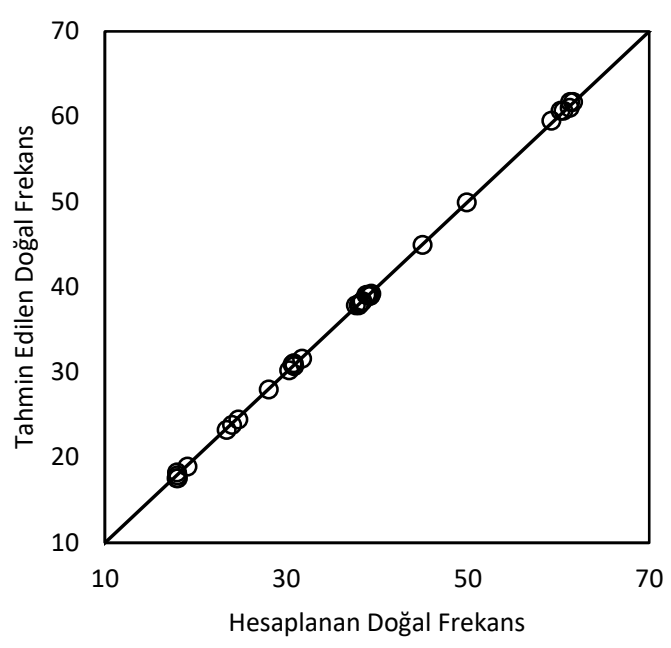

(b) Model 2

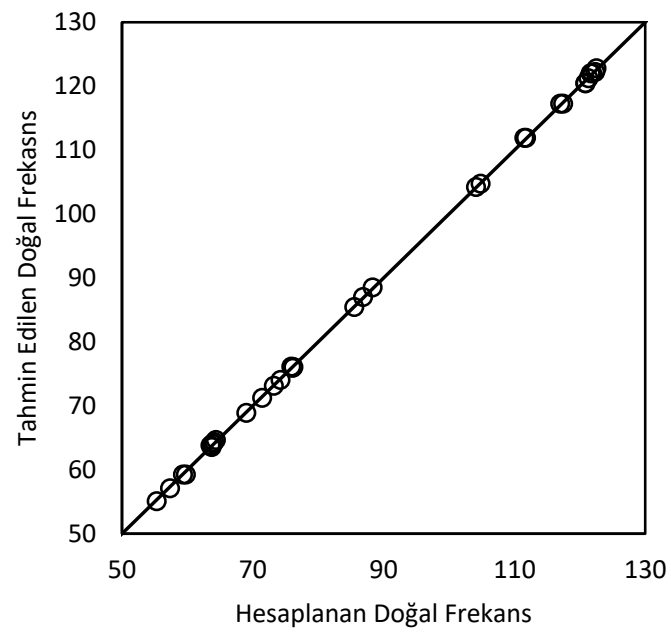

(c)Model 3

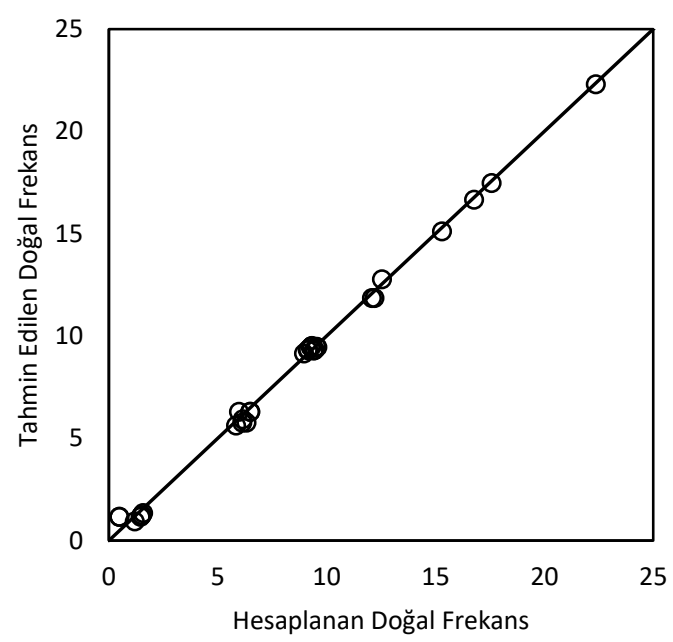

(d)Model $4 \omega_{1}$

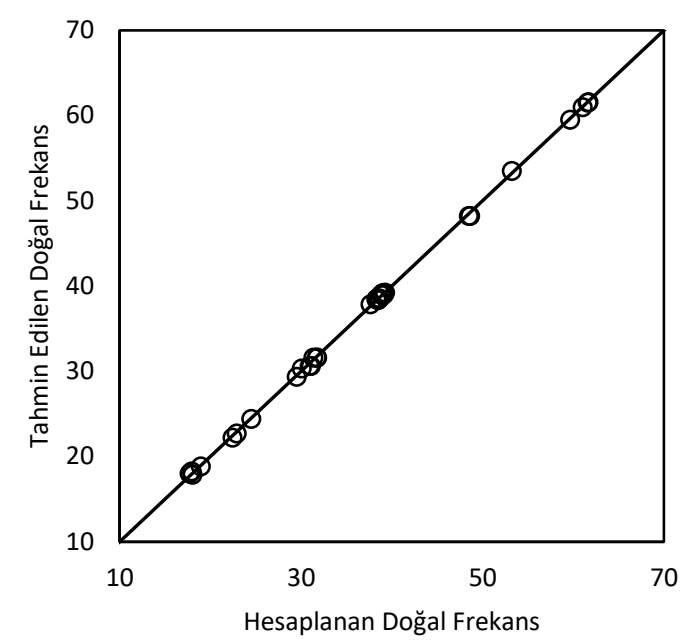

(e)Model $4 \omega_{2}$

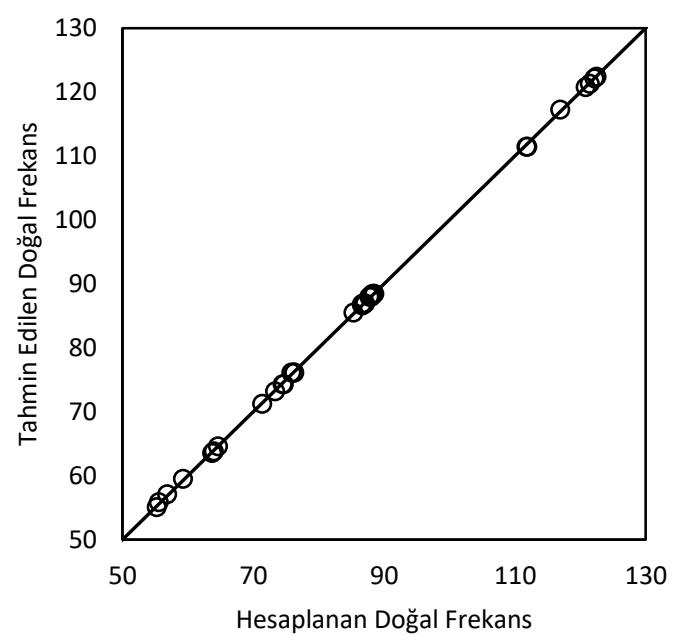

(e)Model $4 \omega_{3}$

Şekil 3. Test modelleri saçılma diyagramı

Figure 3. The scatter diagrams of the test models

Modelin güvenilirliğini kontrol etmek amaciyla Zhang vd. (2016) ile Blevins (1979) tarafindan gerçekleştirilen çalışmalar kullanılmıştır. Karşılaştırmalı sonuçlar Tablo 7'de verilmiştir. Hata değerleri, iki kaynaktan alınan kontrol verileri ile yapılan karşılaştırmada çıkan en büyük fark dikkate alınarak hesaplanmıştır.

$\%$ Hata $=\left|\frac{\omega_{\text {hesap }}-\omega_{\text {tah } \min }}{\omega_{\text {hesap }}}\right| \times 100$ 
Tablo 7. GRYSA modeli ile elde edilen doğal frekans değerleri ile kontrol verilerinin karşılaştırması Table 7. The comparison of the test data and the values of natural frequencies obtained by GRNN model

\begin{tabular}{ccccc}
\hline & $\beta=0.10$ & $\boldsymbol{\omega}_{1}$ & $\boldsymbol{\omega}_{\mathbf{2}}$ & $\boldsymbol{\omega}_{\mathbf{3}}$ \\
\hline$k_{1}=k_{3}=\infty, k_{2}=k_{4}=0$ & & 9,7438 & 39,3532 & 88,7014 \\
\multirow{3}{*}{0.50} & Blevins (1976) & 9,7347 & 39,3620 & 88,7146 \\
& Zhang ve diğ, (2016) & 9,7464 & 39,3512 & 88,6979 \\
& GRYSA Modeli & 0,12 & 0,03 & 0,02 \\
\hline \multirow{2}{*}{1,00} & Hata \% & 9,3563 & 38,9752 & 88,3250 \\
& Blevins (1976) & 9,3207 & 39,0108 & 88,3806 \\
& Zhang ve diğ,(2016) & 9,3657 & 38,9656 & 88,3104 \\
\hline
\end{tabular}

Tablo 7'de görüldüğü gibi karşılaştırılan doğal titreşim frekansları arasındaki fark, akışkan hızının artması ile artmaktadır. Bu çalışma kapsamında geliştirilen GRYSA modelleri Blevins (1979) tarafından yapılan çalışmaya daha yakın sonuç vermektedir. Hata değerleri için en büyük farklar dikkate alındığından $u=1,00$ için Zhang vd, (2016) çalışması ile GRYSA modelleri karşılaştırmasına ilişkin sonuçlar; 1. mod için \% 0,48, 2. mod için $\% 0,12$ ve 3 . mod için \% 0,08 olarak hesaplanmıştır.

\section{Sonuç ve tartışma}

$\mathrm{Bu}$ çalışmada akışkan taşıyan borunun doğal titreşim frekansının, direngenlik katsayısına bağlı GRYSA modelleri oluşturulmuştur. Akışkan-yapı etkileşimi ile Hamilton prensibi kullanılarak akışkan taşıyan borunun hareket denklemi elde edilmiştir. Boyutsuzlaştırılan diferansiyel denklemler analitik yöntemle çözümlenerek doğal titreşim frekansı değerleri hesaplanmıştır. Klasik ve klasik olmayan mesnet şartlarını temsil edecek şekilde 43 farklı kombinasyon, 3 farklı akışkan hızı dikkate alınarak analiz edilmiş ve 387 veri elde edilmiştir. Rijitlik ve akışkan hızı arttıkça doğal titreşim frekansı değerlerinin azaldığ 1 gözlenmiştir. Akışkan hızının 0,20 olması durumunda ankastre-ankastre mesnet şartları altında elde edilen frekans değerleri ilk üç mod için sirası ile 22,3629, 61,6576, 120,8866 olarak hesaplanmıştır. Bu değerler çalışma kapsamında elde edilen en büyük doğal frekans değerleridir. Mesnet koşulları ve doğal titreşim frekansı arasındaki ilişki Genelleştirilmiş Regresyon Yapay Sinir A $\breve{g} 1$ (GRYSA) yöntemi ile MATLAB yazılımı kullanılarak oluşturulan ileri beslemeli geriye yayınım metodu (İBGY) yardımıyla tanımlanmıştır. 4 eğitim modeli ile gerçekleştirilen çalışma sonuçlarında, hesaplanan ve tahmin edilen değerler arasındaki farkı ifade eden hata değeri \% 0,02' ye kadar düşmektedir. Akışkan hızının 1,00 olması durumunda elde edilen en büyük hata \% 0,48 'dir. En büyük hatanın \% 0,48 olarak belirlenmesi, GRYSA yönteminin farklı mesnet şartları altında doğal titreşim frekansı hesabında hız kazandıran alternatif bir yöntem olarak kullanılabileceğini göstermektedir.

\section{Kaynaklar}

[1]Aldraihem, O. J. (2007). Analysis of the dynamic stability of collar-stiffened pipes conveying fluid, Journal of sound and vibration, 300(3-5), 453-465.

[2] Al-Hilli, A. H. (2013). Free vibration characteristics of elastically supported pipe conveying fluid, Alnahrain Journal For Engineerıng Sciences, 16(1), 9-19.

[3] Alp, M, \& Cigizoglu, H. K. (2010). Farklı yapay sinir ağı metodları ile yağış-akış ilişkisinin modellenmesi, İTÜ Dergisi/d, 3(1).

[4] Blevins, R. D, (1979). Formulas for natural frequency and mode shape.

[5] Cigizoglu, H. K. \& Kişi, Ö. (2005). Flow prediction by three back propagation techniques using k-fold partitioning of neural network training data, Hydrology Research, 36(1), 49-64.

[6] Dağlı, B. Y. \& Sınır, B. G. (2015). Dynamics of transversely vibrating pipes under non-classical 
boundary conditions, Universal Journal of Mechanical Engineering, 3(2), 27-33.

[7] Dagli, B. Y. \& Ergut, A. (2019). Dynamics of fluid conveying pipes using Rayleigh theory under nonclassical boundary conditions, European Journal of Mechanics-B/Fluids, 77, 125-134.

[8] Han, S. M., Benaroya, H., \& Wei, T. (1999). Dynamics of transversely vibrating beams using four engineering theories, Journal of Sound and vibration, 225(5), 935-988.

[9] Liu, Z., Yin, Y., Wang, F., Zhao, Y., \& Cai, L. (2013). Study on modified differential transform method for free vibration analysis of uniform EulerBernoulli beam, Structural Engineering and Mechanics, 48(5), 697-709.

[10] Munson, B. R., Okiishi, T. H., Huebsch, W. W. \& Rothmayer, A. P. (2013). Fluid mechanics, Singapore: Wiley.

[11] Laursen, E. M. (1960). Scour at bridge crossings. Journal of the Hydraulics Division, 86(2), 39-54.

[12] Paidoussis, M. P., \& Issid, N. T. (1974). Dynamic stability of pipes conveying fluid, Journal of sound and vibration, 33(3), 267-294.
[13] Samarasinghe, S. (2016). Neural networks for applied sciences and engineering: from fundamentals to complex pattern recognition, Auerbach publications

[14] Tayfur, G. (2014). Soft computing in water resources engineering: Artificial neural networks, fuzzy logic and genetic algorithms, WIT Press,

[15] Tayfur, G. (2017). Modern optimization methods in water resources planning, engineering and management, Water Resources Management, 31(10), 3205-3233,

[16] Yi-Min, H., Yong-Shou, L., Bao-Hui, L., YanJiang, L., \& Zhu-Feng, Y. (2010). Natural frequency analysis of fluid conveying pipeline with different boundary conditions, Nuclear Engineering and Design, 240(3), 461-467.

[17] Wiggert, D. C. \& Tijsseling, A. S. (2001). Fluid transients and fluid-structure interaction in flexible liquid-filled piping, Applied Mechanics Reviews, 54(5), 455-481.

[18] Zhang, T., Ouyang, H., Zhang, Y. O., \& Lv, B. L. (2016). Nonlinear dynamics of straight fluidconveying pipes with general boundary conditions and additional springs and masses, Applied Mathematical Modelling, 40(17-18), 7880-7900. 